\title{
Bidirectional FcRn-dependent IgG transport in a polarized human intestinal epithelial cell line
}

\author{
Bonny L. Dickinson, ${ }^{1}$ Kamran Badizadegan, ${ }^{2}$ Zhen Wu, ${ }^{3}$ Jeremy C. Ahouse, ${ }^{3}$ \\ Xiaoping Zhu, ${ }^{4}$ Neil E. Simister, ${ }^{3,5}$ Richard S. Blumberg, ${ }^{4,5}$ and Wayne I. Lencer ${ }^{1,5}$ \\ ${ }^{1}$ The Combined Program in Pediatric Gastroenterology and Nutrition, Department of Pediatrics, and \\ ${ }^{2}$ Department of Pathology, Children's Hospital, Harvard Medical School, Boston, Massachusetts 02115, USA \\ ${ }^{3}$ Rosensteil Center for Basic Biomedical Sciences, W.M. Keck Institute for Cellular Visualization, and Biology Department, \\ Brandeis University, Waltham, Massachusetts 02254, USA \\ ${ }^{4}$ Division of Gastroenterology, Brigham and Women's Hospital and the Department of Medicine, Harvard Medical School, \\ Boston, Massachusetts 02115, USA \\ ${ }^{5}$ Harvard Digestive Diseases Center, Boston, Massachusetts 02115, USA
}

Address correspondence to: Wayne I. Lencer, Gastrointestinal Cell Biology, Children's Hospital, 300 Longwood Avenue, Boston, Massachusetts 02115, USA. Phone: (617) 355-8599; Fax: (617) 730-0404; E-mail: lencer@a1.tch.harvard.edu, or,

Richard S. Blumberg, Thorn, 1410 Brigham and Women's Hospital, 75 Francis Street, Boston, Massachusetts 02115, USA. Phone: (617) 732-6917, Fax: (617) 264-5185, E-mail: rblumberg@rics.bwh.harvard.edu.

J.C. Ahouse's present address is: Millennium Predictive Medicine, Cambridge, Massachusetts, 02139, USA.

Received for publication March 31, 1999, and accepted in revised form August 16, 1999.

The MHC class I-related Fc receptor, FcRn, mediates the intestinal absorption of maternal IgG in neonatal rodents and the transplacental transport of maternal IgG in humans by receptor-mediated transcytosis. In mice and rats, expression of FcRn in intestinal epithelial cells is limited to the suckling period. We have recently observed, however, clear expression of FcRn in the adult human intestine, suggesting a function for FcRn in intestinal IgG transport beyond neonatal life in humans. We tested this hypothesis using the polarized human intestinal T84 cell line as a model epithelium. Immunocytochemical data show that FcRn is present in T84 cells in a punctate apical pattern similar to that found in human small intestinal enterocytes. Solute flux studies show that FcRn transports IgG across T84 monolayers by receptor-mediated transcytosis. Transport is bidirectional, specific for FcRn, and dependent upon endosomal acidification. These data define a novel bidirectional mechanism of IgG transport across epithelial barriers that predicts an important effect of FcRn on IgG function in immune surveillance and host defense at mucosal surfaces.

J. Clin. Invest. 104:903-911 (1999).

\section{Introduction}

Steady-state levels of IgG in the blood of adult mice, and likely all mammals, depend on IgG catabolism mediated in part by the MHC class I-related Fc receptor, FcRn (1). FcRn also mediates vectorial transport of IgG across certain epithelial barriers. In suckling mice and rats, intestinal absorption of maternal IgG from breast milk into the systemic circulation depends on FcRn (2). In humans, maternofetal transfer of IgG across the placenta also likely depends on FcRn (3). Thus, FcRn plays critical and well-documented roles in the regulation of IgG metabolism in adults and in the acquisition of humoral immunity in early life. These effects on the physiology of IgG in vivo result from the action of FcRn as an intracellular trafficking receptor (4).

FcRn has been cloned from the rat, mouse, and human. The molecule is expressed as a heterodimer composed of a glycosylated heavy $(\alpha)$ chain $(51 \mathrm{kDa}$ in rodents and $40-45 \mathrm{kDa}$ in humans) associated noncovalently with $\beta_{2}$-microglobulin $\left(\beta_{2} \mathrm{M}\right)(5)$. Binding of IgG to FcRn requires contact between solvent-exposed peptide sequences in the $\mathrm{CH} 2$ and $\mathrm{CH} 3$ domains of IgG and the $\alpha 1$ and $\alpha 2$ domains of FcRn, together with a single contact site in $\beta_{2} \mathrm{M}(6-11)$. A hallmark of FcRn interaction with IgG is its $\mathrm{pH}$ dependence, showing high-affinity binding at acidic $\mathrm{pH}(\mathrm{pH} \leq 6.5)$ and weak or no binding at neutral $\mathrm{pH}(\mathrm{pH} \geq 7.0)(12,13)$. $\mathrm{FcRn}$ is the only Fcy receptor that exhibits MHC class I structure, and the only Fc $\gamma$ receptor to exhibit $\mathrm{pH}$ dependency in ligand binding.

The function of FcRn in the intestine of suckling mice and rats has been well documented (14). In neonatal mice and rats, FcRn is expressed at high levels by intestinal epithelial cells and mediates absorption of IgG by receptor-mediated transcytosis. FcRn expression in the neonatal rodent is developmentally downregulated, resulting in nearly complete loss of intestinal FcRn at the time of weaning (15-17). Consequently, a role for FcRn beyond neonatal life has been slow to emerge. However, we have recently observed expression of FcRn in adult rat hepatocytes (18) and in adult human intestinal epithelial cells (19). The FcRn detected in isolated human small 
intestinal epithelial cells had identical predicted amino acid sequence to that expressed by human placenta (20). These data raised the possibility that FcRn may function to transport IgG across the adult human intestinal epithelium.

In this study, we show that the polarized human intestinal epithelial cell line T84 transports IgG by receptor-mediated transcytosis. Transport is bidirectional and dependent on FcRn. These data define the function of FcRn in a model intestinal epithelial cell line, and indicate that FcRn may function in vivo to transport IgG across the epithelial barrier of the intestine and possibly across other mucosal surfaces of the adult human. As such, these data predict a profound effect of FcRn on IgG function in immune surveillance and host defense.

\section{Methods}

Cell lines and human tissue. Human cell lines T84, HT29, Caco-2, CEM, 293, U937, CHO, and MOLT-4 were purchased from American Type Culture Collection (Rockville, Maryland, USA). Normal adult human small intestine was obtained from patients undergoing gastric bypass surgery, and epithelial cells were nonenzymatically isolated as described $(21,22)$. T84 cells (passages 28-61; gift from K. Barrett, University of California San Diego, San Diego, California, USA) were grown on Transwell inserts (Corning-Costar Corp., Cambridge, Massachusetts, USA) as described previously (23). Transcytosis experiments were performed in HBSS supplemented with 10 mM HEPES (pH 7.4) (HBSS+) (Sigma Chemical Co., St. Louis, Missouri, USA). T84, Caco-2, or HT29 cells were cell surfacebiotinylated or metabolically labeled as described previously $(24,25)$.

Antibodies. Anti-FcRn antibodies purified from 2 rabbit antipeptide antisera were used, one raised against amino acids $112-125$ of human FcRn (3), the other against amino acids 174-188 (K. McCarthy and N.E. Simister, manuscript in preparation). Polyclonal antisera were also raised in mice against the $\alpha 2$ domain of human FcRn expressed as a GST fusion protein in Escherichia coli. These antisera did not cross-react with either MHC class I or CD1d, as defined by Western blotting of 721.220, 721.220-CD1d transfectant, Jurkat, THP1, and HeLa cells. HeLa cells cotransfected with FcRn $\alpha$ chain and $\beta_{2} \mathrm{M}$ expression plasmids were used as positive controls (data not shown).

Western and Northern blots. T84, HT29, Caco-2, 293 cells transfected with a cDNA-encoding human FcRn $\alpha$ chain (20), untransfected 293 cells, and normal human small intestinal cells (19) were extracted in 5\% SDS in water. Protein extracts were resolved on gradient polyacrylamide denaturing Tris-glycine gels (Novex, San Diego, California, USA) and transferred onto PVDF (Novex) or nitrocellulose (Bio-Rad Laboratories Inc., Hercules, California, USA). Blots were probed with affinity-purified anti-FcRn peptide antibody, and bound antibody was detected with horseradish peroxidase-conjugated goat anti-rabbit anti- body and enhanced chemiluminescence (Renaissance Chemiluminescence Reagent; NEN Life Science Products Inc., Boston, Massachusetts, USA). For deglycosylation studies, protein extracts $(10 \mu \mathrm{g}$ total protein) prepared in 5\% SDS in water were deglycosylated with PNGase F (New England Biolabs Inc., Beverly, Massachusetts, USA), separated by SDS-PAGE under reducing and nonreducing conditions, and blotted for $\mathrm{FcRn}$ as already described here.

For Northern blots, total cellular RNA was extracted from T84, HT29, Caco-2, CEM, 293-FcRn, 293 cells, and normal human small intestinal cells using Ultraspec (Biotecx Laboratories Inc., Houston, Texas, USA). RNA $(10 \mu \mathrm{g} /$ lane) was run on a denaturing agarose gel and transferred to a Biotrans Nylon Membrane (ICN Radiochemicals Inc., Irvine, California, USA). The blot was hybridized with $2 \times 10^{6} \mathrm{cpm} / \mathrm{mL}$ of ${ }^{32}$ P-labeled probe derived from the 120-bp Xmn-EcoRI fragment of a human placental FcRn cDNA clone (3). The blot was hybridized in QuikHyb (Stratagene, La Jolla, California, USA), washed, exposed on a phosphor screen (Eastman Kodak Co., Rochester, New York), and analyzed on a PhosphorImager (Molecular Dynamics, Sunnyvale, California, USA).

RT-PCR and nested PCR. Total RNA was isolated from T84, MOLT-4, and U937 cells with Trizol reagent (GIBCO BRL, Gaithersburg, Maryland, USA). RNA (2 $\mu \mathrm{g})$ was reverse-transcribed to cDNA with an oligo-dT primer (Promega Corp., Madison, Wisconsin, USA) and avian myeloblastosis virus reverse transcriptase (Promega Corp.). The cDNA samples were used as a template in a nested PCR reaction, performed to increase amplification of Fc $\gamma \mathrm{RI}$ transcripts in resting monocytes as described previously (26). First- and second-round primers specific for $\mathrm{F} c \gamma \mathrm{RI}$ cDNA were identical to those designed by van de Winkel et al. (27). The first-round PCR product (30 cycles) was diluted 1:2.5 and amplified with nested primers specific for Fc $\gamma \mathrm{RI}$ or with primers specific for $\beta$-actin. In addition to the major 800-bp Fc $\gamma R$ I product, 2 other transcripts ( 700 and 1,000 bp) were amplified, likely reflecting the multiple transcripts for FcyRI observed in human monocytes $(26,28)$.

Immunohistochemistry and confocal microscopy. Normal human small intestine and polarized T84 cell monolayers were embedded in Tissue-Tek OCT Compound (Sakura-Finetek Inc., Torrance, California, USA) for frozen sectioning on a Leica CM3050 cryomicrotome (Leica, Nussloch, Germany). Frozen sections $(5 \mu \mathrm{m})$ were air-dried at room temperature, fixed in $4 \%$ paraformaldehyde in PBS, washed in PBS, and blocked in 10\% normal goat serum (Zymed Laboratories Inc., South San Francisco, California, USA). Sections were stained with an affinity-purified rabbit anti-human FcRn peptide antibody (amino acids 174-188) or a mouse polyclonal anti-FcRn antiserum diluted in the blocking solution and detected with appropriate fluorophore-conjugated secondary antibodies for epifluorescence microscopy. For some experiments, T84 cells grown on glass coverslips or Transwell inserts were 

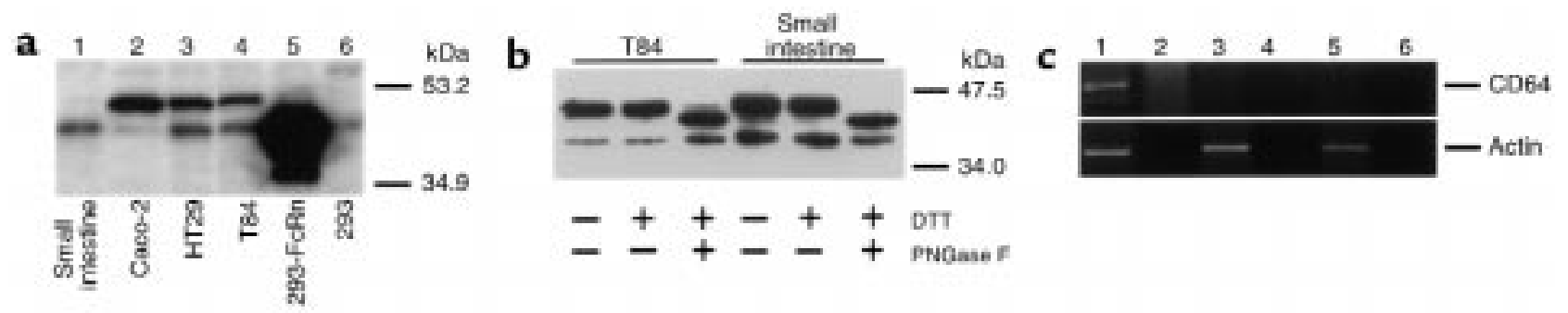

Figure 1

FcRn expression in normal adult human small intestine and human intestinal epithelial cell lines. Western blots of total cellular protein (13 $\mu \mathrm{g}$ protein per lane, $\mathbf{a} ; 10 \mu \mathrm{g}$ protein per lane, $\mathbf{b})$ isolated from the indicated source using affinity-purified rabbit antisera raised against

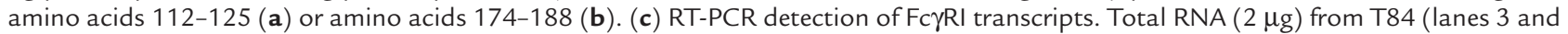
4), MOLT-4 (lanes 5 and 6; negative control), and U937 (lanes 1 and 2; positive control) cell lines was incubated with an oligo-dT primer with (odd-numbered lanes) or without (even-numbered lanes) avian myeloblastosis virus-RT (AMV-RT), and a nested PCR was performed with primers specific for Fc $\gamma \mathrm{RI}$ cDNA (top) or for $\beta$-actin (bottom).

stained with rhodamine-labeled IgG or were directly fixed in $4 \%$ paraformaldehyde, washed in PBS, and stained with the aforementioned anti-FcRn antibodies and in combination with antibodies against tight junction protein ZO-1 (Zymed Laboratories Inc.). Intact monolayers were mounted on glass slides for epifluorescence and/or confocal microscopy. All staining reactions were accompanied by a negative control that consisted of an affinity-purified, isotype-matched nonspecific antiserum. All sections prepared for fluorescent microscopy were mounted in ProLong antifade reagent (Molecular Probes Inc., Eugene, Oregon, USA) and viewed using either a Bio-Rad MRC-1024 confocal microscope or a Zeiss Axiophot microscope equipped with a Spot digital camera (Diagnostic Instruments, Sterling Height, California, USA). Electronic images were captured and edited in Adobe Photoshop (Adobe Systems Inc., Mountain View, California, USA).

For binding studies, T84 cells grown on glass coverslips were incubated at $4^{\circ} \mathrm{C}$ with $60 \mathrm{nM}$ IgG-rhodamine in the absence or presence of a 1,000-fold molar excess of underivatized IgG in $\mathrm{pH} 6.0$ or $\mathrm{pH} 8.0$ buffer. Coverslips were processed for epifluorescence microscopy as described previously (23).

Transepithelial IgG flux studies. Purified human IgG (IgG) and chicken IgG (IgY) (Jackson ImmunoResearch Laboratories Inc., West Grove, Pennsylvania, USA) were biotinylated with sulfo-NHS-biotin (Pierce Chemical Co., Rockford, Illinois, USA). Protein concentrations were determined by the bicinchoninic acid method (Pierce Chemical Co.) and confirmed by SDSPAGE and ligand blot. T84 monolayers exhibiting high electrical resistances $\left(800-1,200 \Omega / \mathrm{cm}^{2}\right)$ were equilibrated in $\mathrm{HBSS}+$, and $60 \mathrm{nM}$ biotin-labeled IgG or IgY (6-600 nM were initially tested) was added to the apical or basolateral reservoirs. As a nonspecific blocker, $0.5 \%$ Teleostean gelatin (Sigma Chemical Co.) was included with ligand. In some studies, unlabeled $\operatorname{IgG}$ or $\operatorname{IgY}(30 \mu \mathrm{M})$ or $0.1 \mathrm{mg} / \mathrm{mL}$ fragment $\mathrm{B}$ of Staphylococcal protein A (Pierce Chemical Co.) was used as a competitive inhibitor. When indicated, T84 cell monolayers were preincubated for 20 minutes with $0.1 \mu \mathrm{M}$ bafilomycin A1 (Sigma Chemical Co.) to inhib- it the vacuolar proton pump (29). Monolayers were incubated for 1 hour with ligand at either $37^{\circ} \mathrm{C}$ or $4^{\circ} \mathrm{C}$, after which an aliquot of the contralateral well buffer was collected and 3-4 similarly treated Transwells were combined. Transported proteins were precipitated by acetone or trichloroacetic acid in the presence of $10 \mu \mathrm{g}$ yeast tRNA (Boehringer Mannheim $\mathrm{GmbH}$, Mannheim, Germany) and were analyzed by SDS-PAGE and ligand blot after reduction with DTT as described previously (30). In some studies, transported proteins were analyzed by ELISA (see later here). In 1 experiment, NIH Image software (version 1.54; National Institutes of Health, Bethesda, Maryland, USA) was used to determine relative band intensities of a scanned avidin blot in which apically and basolaterally directed IgG transport was analyzed.

ELISA. For analysis by quantitative ELISA, samples were first microconcentrated by centrifugation (Amicon Inc., Beverly, Massachusetts, USA). MaxiSorp 96well microtiter plates (NUNC A/S, Roskilde, Denmark) were coated overnight at $4^{\circ} \mathrm{C}$ with $10 \mu \mathrm{g} / \mathrm{mL}$ of either goat anti-human IgG or rabbit anti-chicken IgY (Jackson ImmunoResearch). Plates were blocked with $1 \%$ BSA in PBS $/ 0.05 \%$ Tween-20, and samples were added to washed plates and incubated for 1 hour at room temperature or overnight at $4^{\circ} \mathrm{C}$. Standards were prepared in duplicate from stock preparations of biotinylated ligands. To detect biotinylated ligands, $0.1 \mu \mathrm{g} / \mathrm{mL}$ streptavidin-horseradish peroxidase in blocking buffer was added, plates were washed again, and 2,2' -azinobis(3-ethylbenthiazoline-6-sulfonic acid) (ABTS; Sigma Chemical Co.) was added as substrate.

\section{Results}

Expression of FcRn in adult buman intestine and intestinal cell lines. Three intestinal epithelial cell lines and enterocytes purified from normal human adult small intestine were assessed for $\mathrm{FcRn}$ protein by Western blot using 2 independently produced antipeptide antisera raised in rabbits (Figure 1, $a$ and $b$ ). An affinity-purified rabbit antiserum raised against amino acids $112-125$ of human FcRn $\alpha 2$ domain detected an immunoreactive $45-\mathrm{kDa}$ band in the enterocyte whole-cell lysate and lysates from human T84, 

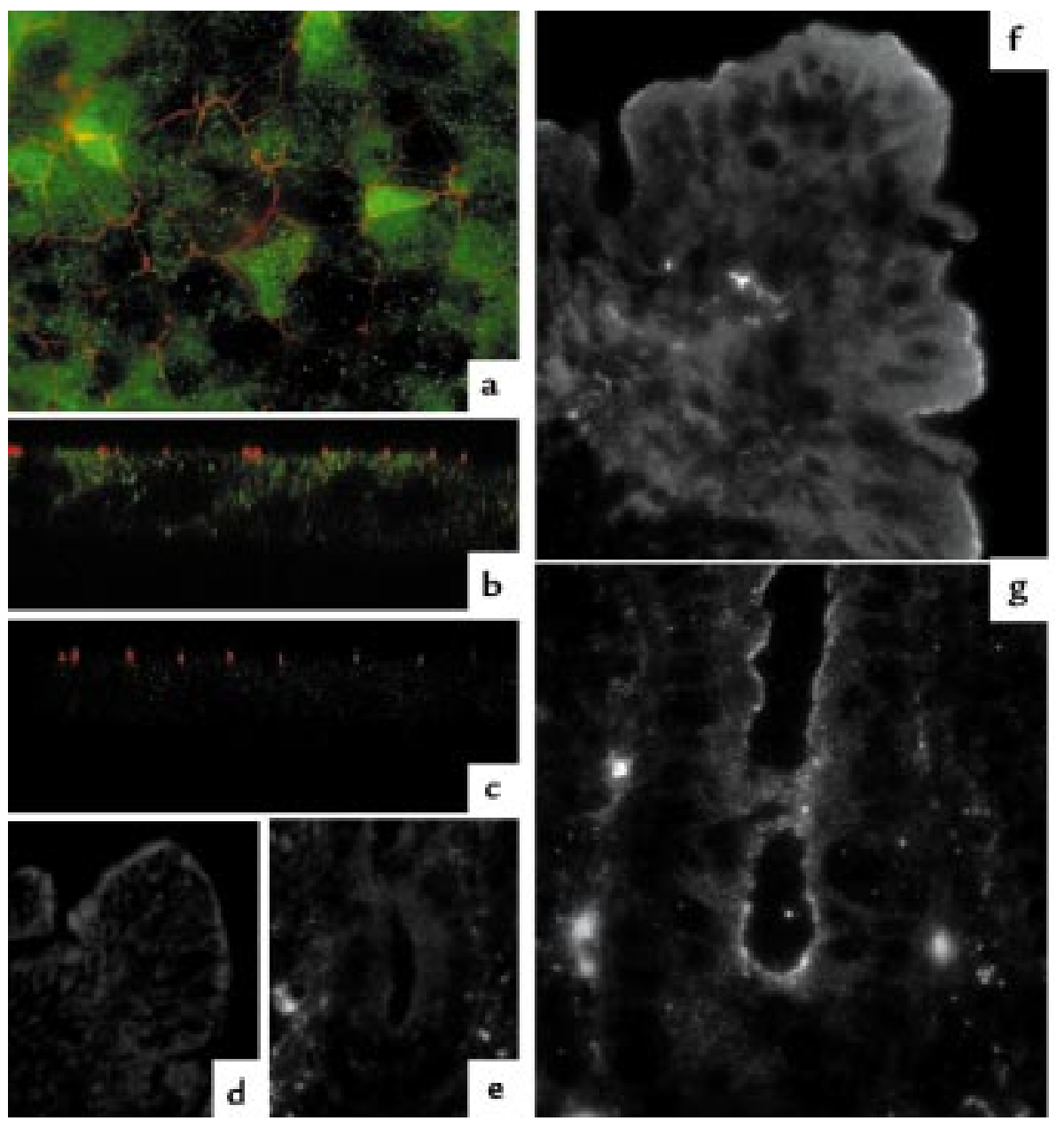

Figure 2

Immunolocalization of FcRn in polarized T84 monolayers (a-c) and normal adult human small intestinal mucosa (d-g). (a) Whole-mount T84 monolayers show a diffuse, punctate staining pattern. The Z0-1 image was captured slightly above the focal plane of FcRn. (b) FcRn staining of whole-mount T84 monolayers viewed as confocal vertical sections. (c) FcRn staining was absent in the presence of an isotype-matched, irrelevant antiserum. (f) Villous enterocytes of normal adult human small intestine show delicate linear staining in the region of the apical cytoplasmic membrane. (g) Crypt enterocytes show an apical and punctate staining pattern visible not only at the level of the apical cytoplasmic membrane, but also in the apical cytoplasm below the level of the apical membrane. (d and e) FcRn staining was absent in the presence of an irrelevant antiserum or with secondary antibody alone (not shown).

HT29, and Caco-2 cell lines (Figure 1a). The human embryonic kidney 293 cell line, transfected (293-FcRn; lane 5) or not transfected (293; lane 6) with full-length human FcRn cDNA cloned from the human placenta (20), served as controls. The $45-\mathrm{kDa}$ band detected is consistent with the known molecular weight of human FcRn heavy chain and migrated with human $\mathrm{FcRn} \alpha$ chain expressed in the 293 transfected cells (lane 5). A second band of approximately $48 \mathrm{kDa}$ was recognized by the antibody in protein lysates of cultured human epithelial cell lines only (lanes 2-4). The molecular identity of this band remains unknown but likely represents a cross-reactive protein rather than an altered form of $\mathrm{FcRn}$, as this band was not detected with a second, affinity-purified rabbit antiserum raised against a different epitope of human FcRn heavy chain (amino acids 174-188) (Figure 1b). Using this antiserum, a $45-\mathrm{kDa}$ band corresponding to the FcRn $\alpha$ chain was detected in both T84 cell and enterocyte whole-cell lysates. The identity of the $45-\mathrm{kDa}$ protein as FcRn was confirmed by the shift in molecular mass after deglycosylation with PNGase F, consistent with the predicted single glycosylation site within the human FcRn $\alpha 2$ domain. A lower band of approximately $40 \mathrm{kDa}$ was also identified in both T84 cell and human enterocyte lysates with this antiserum. This protein likely represents a cross-reactive protein, as it was neither detected with the antisera directed against amino acids 112-125 (Figure 1a) nor deglycosylated with PNGase F (Figure 1b). These results were verified using enterocytes purified from 3 different adult human small intestinal biopsies (data not shown). Taken together, these data indicate that, like enterocytes purified from the adult human small intestine, the T84, HT29, and Caco- 2 cell lines express the $45-\mathrm{kDa}$ glycosylated $\alpha$ chain of FcRn. To confirm these results, a Northern blot analysis was performed with total RNA obtained from normal adult 


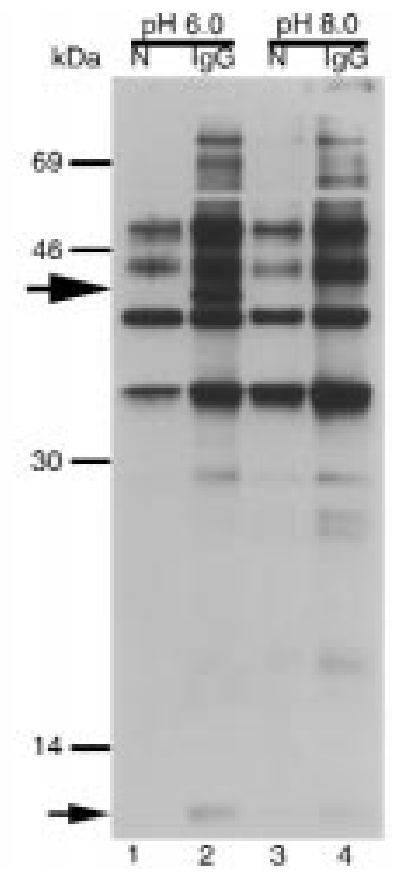

\section{Figure 3}

Functional expression of FcRn in polarized T84 cells. T84 cells grown on collagen-coated Transwells were cell surface-biotinylated and solubilized at either $\mathrm{pH} 6.0$ or $\mathrm{pH} 8.0$ lysates were incubated with Sepharose beads $(N)$ or beads coupled to $\lg G(\lg G)$. Immunoprecipitated proteins were analyzed by SDS-PAGE and avidin blot. A $12-\mathrm{kDa}$ band consistent with the mobility of $\beta_{2} \mathrm{M}$ (small arrow) and a 45$\mathrm{kDa}$ band consistent with the mobility of human $\mathrm{FcRn} \alpha$ chain (large arrow) were immunoprecipitated by IgG-coupled beads at $\mathrm{pH} 6.0$ but not at $\mathrm{pH} 8.0$.

human small intestinal enterocytes and the human intestinal Caco-2, HT29, and T84 epithelial lines (data not shown). A ${ }^{32}$ P-labeled cDNA probe encoding the $3^{\prime}$ untranslated region of human placental FcRn cDNA hybridized with a single, abundantly expressed 1.5 $\mathrm{kb}$ band in all samples examined. These data were verified by RT-PCR using oligonucleotide primers specific for the $\alpha 2$ domain of the human FcRn heavy chain, which amplified a 242-bp specific product in the 3 intestinal cell lines and human small intestinal enterocytes (data not shown).

FcRn expression in polarized T84 cells. We selected the T84 cell line for further study based on the results reported here and the ability of T84 cells to form welldifferentiated polarized monolayers with high electrical resistances. We determined whether T84 cells express Fc $\gamma \mathrm{RI}(\mathrm{CD} 64)$, the only other Fc $\gamma$ receptor that displays high affinity for monomeric IgG (31). As shown in Figure 1c, nested RT-PCR yielded an 800-bp fragment specific for CD64 in the human promonocyte cell line U937 (lane 1, top) but not in polarized T84 cells (lane 3, top) or in the human T-lymphoblast cell line MOLT-4 (predicted to be negative for Fc $\gamma \mathrm{RI}$; lane 5 , top). RT-PCR amplification of human $\beta$-actin provided an internal control for each reaction (Figure 1c; lanes 1, 3, and 5, bottom). Thus, the results of IgG flux studies in T84 cells (described later here) were not confounded by cotransport via IgG binding to Fc $\gamma \mathrm{RI}$.

Expression of human FcRn in polarized T84 cells and normal human small intestine was confirmed by immunohistochemistry using 2 independently raised antibodies (see Methods). T84 cells stained with anti$\mathrm{FcRn}$ antibodies showed a punctate staining pattern (Figure 2a), with the majority of signal close to the apical membrane at or just below the level of the tight junctional ZO-1 expression (Figure $2 \mathrm{~b}$ ). Frozen sections of adult small intestinal mucosa showed distinct villous and crypt staining patterns. Villous enterocytes showed a delicate linear staining pattern at the apical membrane (Figure 2f), which, on tangential sections, appeared to consist of uniform small dots (data not shown). The staining in crypt enterocytes was also apical and punctate, but there was more variability in the size and dis- tribution of the signal, and positive signal was also identified in the apical cytoplasm below the level of the apical membrane (Figure 2g). In this respect, the T84 staining pattern resembled to a greater extent the pattern seen in crypt enterocytes. Positive immunofluorescence for FcRn was not present in identical T84 monolayers (Figure 2c) or frozen sections (Figure 2, d and e), treated with nonimmune serum and an irrelevant affinitypurified antiserum, respectively. These data corroborate and extend previous evidence that FcRn is expressed in adult human intestine (19), and show that T84 cells express FcRn in a pattern similar to that found in crypt enterocytes of normal human small intestine.

Functional activity on the cell surface. To test the function of FcRn in IgG transport, we first examined the specificity and $\mathrm{pH}$ dependency of IgG binding to FcRn solubilized from total T84 cell lysates in vitro. Cell-surface membrane proteins were labeled with biotin, solubilized, and precipitated by Sepharose beads covalently coupled to human IgG using methods modified from previous studies (24). Figure 3 shows that a $12-\mathrm{kDa}$ band consistent with the mobility of $\beta_{2} \mathrm{M}$ (small arrow) and a $45-\mathrm{kDa}$ protein consistent with the mobility of human FcRn $\alpha$ chain (large arrow) were precipitated (Figure 3, lane 2). Ligand precipitation by IgG-coupled beads was specific and displayed a $\mathrm{pH}$-dependency characteristic for $\mathrm{Fc}$ binding to $\mathrm{FcRn}$ : present at $\mathrm{pH} 6.0$ and absent at pH 8.0 (lane 2 vs. lane 4) (13, 20, 32). Nearly identical results were obtained by ligand precipitation of solubilized cell-surface proteins from HT29 cells labeled with ${ }^{125}$ I and from Caco-2 cells metabolically labeled with $\left[{ }^{35} \mathrm{~S}\right]$ methionine (data not shown). The functional integrity of FcRn in T84 cells was confirmed using cells grown on glass coverslips. As assessed by epifluorescence microscopy (Figure 4), binding of rhodamine-labeled IgG to T84 cell surfaces at $4^{\circ} \mathrm{C}$ was $\mathrm{pH}$-dependent (apparent at $\mathrm{pH} 6.0$ but not at $\mathrm{pH}$ 8.0) and strongly reduced in the presence of excess competing unlabeled IgG. When incubated at $37^{\circ} \mathrm{C}$, rhodamine-labeled IgG was redistributed into punctate intracellular vesicles consistent with uptake into endosomal vesicles (data not shown).

Receptor-mediated transcytosis of IgG in T84 cells. FcRndependent IgG transport was measured by transepithelial flux of biotin-labeled human IgG. Figure 5a shows that after 1 hour at $37^{\circ} \mathrm{C}$, intact human $\operatorname{IgG}(60 \mathrm{nM})$ applied to apical or basolateral cell surfaces was transported in both lumenal and ablumenal directions across T84 cell monolayers, as assessed by SDS-PAGE and ligand blot. Transport of heavy $(55-\mathrm{kDa})$ and light $(25-\mathrm{kDa})$ chains of IgG was detected in monolayers incubated at 


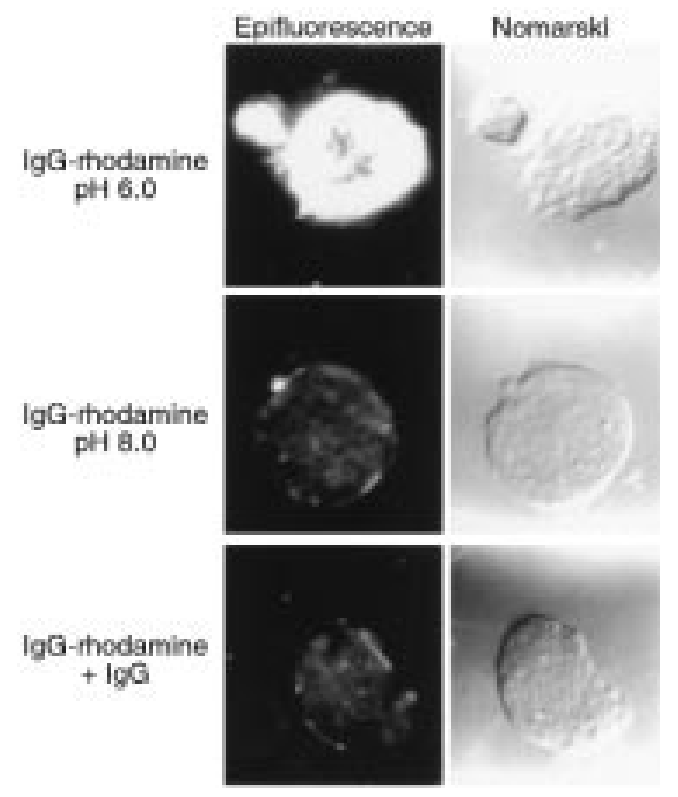

\section{Figure 4}

Binding of rhodamine-labeled IgG to T84 cell surfaces. T84 cells grown on glass coverslips were incubated at $4^{\circ} \mathrm{C}$ with rhodaminelabeled IgG at pH 6.0 or pH 8.0 in the presence or absence of excess competing nonlabeled IgG. Ligand binding was assessed by epifluorescence and Nomarski bright-field microscopy.

$37^{\circ} \mathrm{C}$ (lanes 1 and 3) but not in monolayers incubated at $4^{\circ} \mathrm{C}$ (lane 2). These data are representative of 7 and 4 independent experiments examining basolaterally directed and apically directed IgG transport, respectively. Thus, transepithelial flux of biotin-labeled IgG did not occur by passive diffusion through intercellular tight junctions or monolayer leaks. These data indicate that IgG can enter both apically and basolaterally directed transcytotic pathways in T84 cells. In a separate experiment like that shown in Figure 5a, the apically directed transport pathway was determined to be approximately 3.6-fold more efficient in IgG transport than the basolaterally directed pathway. In this experiment, band intensities were compared by densitometry and measured against control IgG heavy and light chains (0.5 ng IgG-biotin standard).

Two experimental approaches were used to show that transcytosis of IgG was receptor-mediated and specific for FcRn. First, we used chicken IgY, which is structurally similar to human IgG but does not bind FcRn $(33,34)$. Apically and basolaterally directed transepithelial transport of human IgG and chicken IgY, both applied at 60 $\mathrm{nM}$, was examined in parallel by avidin blot (Figure $5 \mathrm{~b}$ ) and by quantitative ELISA (Figure $5 \mathrm{c}$ ). Figure $5 \mathrm{~b}$ shows that after 1 hour at $37^{\circ} \mathrm{C}$, human IgG $(60 \mathrm{nM})$ applied to the basolateral cell surface was transported across monolayers incubated at $37^{\circ} \mathrm{C}$ (lane 3 ) but not across monolayers incubated at $4^{\circ} \mathrm{C}$ (lane 4$)$. In contrast, chicken IgY did not cross T84 cell monolayers in either direction at $37^{\circ} \mathrm{C}$ (Figure 5b, lanes 2 and 5). A nonspecific avidin-reactive protein band migrating just below the IgY heavy chain was detected in all lanes after TCA pre- cipitation. This band is a contaminant of the TCA precipitation technique, as it was also present in precipitates containing only the carrier protein, yeast tRNA. These data are representative of 3 independent studies.

We also examined the specificity of basolaterally directed transport in separate studies by quantitative ELISA (Figure 5c). Transcytosis of IgG was detected in monolayers incubated at $37^{\circ} \mathrm{C}$ but not at $4^{\circ} \mathrm{C}(8.14 \pm 2.89$ vs. $2.25 \pm 0.90 \mathrm{pM} / \mathrm{h}$ per $\mathrm{cm}^{2}$; mean $\left.\pm \mathrm{SEM}\right)$, and transport of $\operatorname{IgY}$ at $37^{\circ} \mathrm{C}$ was not significantly different from $4^{\circ} \mathrm{C}$ controls $\left(1.77 \pm 0.93\right.$ vs. $0.68 \pm 0.18 \mathrm{pM} / \mathrm{h}$ per $\mathrm{cm}^{2}$; mean $\pm \mathrm{SEM})(n=4 ; P=0.05$ by ANOVA). In addition, we find that horseradish peroxidase, an accepted marker for fluid-phase uptake (non-receptor-mediated endocytosis), is not transported at detectable levels (0.024 pM) across intact T84 monolayers in either direction. Thus, in contrast to the transcytotic routing of FcRn-IgG complexes through the cell, fluid-phase cargo (horseradish peroxidase and $\operatorname{IgY}$ ) is likely degraded via the lysosomal degradative pathway or is inefficiently transported.

To confirm and extend these results, we examined IgG-biotin transport in the presence and absence of excess native human IgG or chicken IgY as competitive inhibitors. Competition experiments were performed with a 500-fold molar excess of native IgG or IgY (30 $\mu \mathrm{M})$ (Figure 6, a and b). Data representative of 4 independent experiments are shown. Basolaterally directed transcytosis of IgG-biotin was blocked completely by excess unlabeled IgG (Figure 6a, lane 5), whereas competition with IgY had no effect (lane 4). Incubations at $37^{\circ} \mathrm{C}$ in the absence of competitive inhibitor (lane 2) and at $4^{\circ} \mathrm{C}$ (lane 3 ) provided positive and negative controls. Similarly, excess native IgG (Figure 6b, lane 4), but not IgY (lane 3), blocked apically directed transcytosis of IgG-biotin.

In another version of this approach, IgG transport was inhibited by competition with fragment B of Staphylococcal protein A. Amino acid residues I253, H310, and $\mathrm{H} 433$ - located at the interface between $\mathrm{CH} 2$ and $\mathrm{CH} 3$ domains of IgG - have been identified by mutagenesis as important for FcRn binding (7). Fragment B of Staphylococcal protein A makes contact with overlapping amino acids in this region (252-254, 308-312, and 433-436; EU numbering) (35) and effectively inhibits IgG binding to FcRn without cross-linking the ligand (9). When used as a competitive inhibitor, fragment $\mathrm{B}$ also completely blocked basolateral-to-apical transport of IgG (Figure 6b, lane 5). Competition with excess IgG (lane 4) and IgY (lane 3) provided positive and negative internal controls, respectively. Taken together, these data show that IgG transepithelial transport across T84 cell monolayers is specific and strictly dependent on binding to $\mathrm{FcRn}$.

pH dependency of IgG transport. FcRn is the only Fc receptor that displays $\mathrm{pH}$ dependency for binding of IgG. Thus, to confirm the specificity for FcRn in IgG transport and to test the idea that FcRn may first bind its ligand within the acidic endosome, we examined the $\mathrm{pH}$ dependency of IgG transcytosis (Figure 6c). The following studies were performed under conditions in which 
the apical and basolateral reservoirs were buffered to $\mathrm{pH}$ 8.0 to inhibit $\operatorname{IgG}$ binding to FcRn at cell surfaces. To demonstrate $\mathrm{pH}$ dependency, T84 cells were incubated in the presence or absence of bafilomycin $\mathrm{A} 1(0.1 \mu \mathrm{M})$. Bafilomycin A1 is a specific inhibitor of the vacuolar $\mathrm{H}^{+}$ ATPase in T84 cells. It collapses $\mathrm{pH}$ gradients in intracellular vesicles but does not interfere greatly with membrane trafficking, as evidenced by studies on transferrin receptor recycling in $\mathrm{CHO}$ cells (36), receptor-mediated uptake, signal transduction, and transcytosis of cholera toxin and botulinum toxin in T84 cells $(29,37)$. Figure $6 \mathrm{c}$ shows that bafilomycin A1 completely inhibited apical-to-basolateral transport of IgG (lane 2). Incubations at $37^{\circ}$ and $4^{\circ} \mathrm{C}$ in the absence of bafilomycin $\mathrm{A} 1$ provided positive and negative internal controls (lanes 3 and 4 , respectively). Identical results were obtained in studies on apically directed IgG transport (data not shown). These data are representative of 4 independent studies ( 2 studies in each direction), and show that FcRn-mediated transepithelial transport of IgG in T84 cells requires the formation of acidic intracellular compartments. However, we cannot exclude the possibility of an indirect effect of bafilomycin A1 on vesicle formation and trafficking. Given the well-known dependence on acidic $\mathrm{pH}$ for $\mathrm{IgG}$ binding to $\mathrm{FcRn}$, these data provide evidence that IgG may enter the transcytotic pathway by binding to FcRn within acidic intracellular compartments rather than at the cell surface, or that both ligand binding within acidic vesicles and bafilomycin A1-sensitive membrane traffic (38) are required.

\section{Discussion}

These studies show that polarized human intestinal T84 cells and normal human adult small intestinal epithelial cells express FcRn. At steady state, FcRn in
T84 cells is localized within apical intracellular vesicles, similar in distribution to that found in crypt enterocytes of native human small intestine. As predicted from the defined function of this molecule in intestinal epithelial cells of suckling mice and rats, we find that FcRn functions in T84 cells to carry IgG across the epithelial barrier by receptor-mediated transcytosis. IgG transport is bidirectional, specific to FcRn, and dependent on endosome acidification. These data define a novel bidirectional mechanism for IgG transport across polarized epithelial barriers.

In the absence of disease, epithelial monolayers lining mucosal surfaces are impervious to solute transport by passive diffusion. This is a fundamental requirement for all transporting epithelia, such as those found in the intestine, lung, and kidney, which function to absorb or secrete solutes and water, often against steep electrochemical and concentration gradients. Thus, very few macromolecules traverse the epithelial barrier intact by passive diffusion (39-42). Some macromolecules, however, may be efficiently transported across epithelial cells by endocytosis into specialized transport vesicles that move across the cell in a process termed transcytosis. This transcellular pathway of macromolecular transport is most often receptor-mediated, as typified by the mechanism for the mucosal secretion of polymeric IgA by the polymeric immunoglobulin receptor (pIgA-R) (43-45), and as described in this report for FcRndependent transport of IgG. Macromolecular transcellular transport can occur by fluid phase or non-receptor-mediated endocytosis, but this pathway is inefficient, and most of the endocytosed cargo is delivered to the lysosome for degradation (46).

The mechanism of FcRn-mediated IgG transport apparent in T84 cells, however, differs from that defined

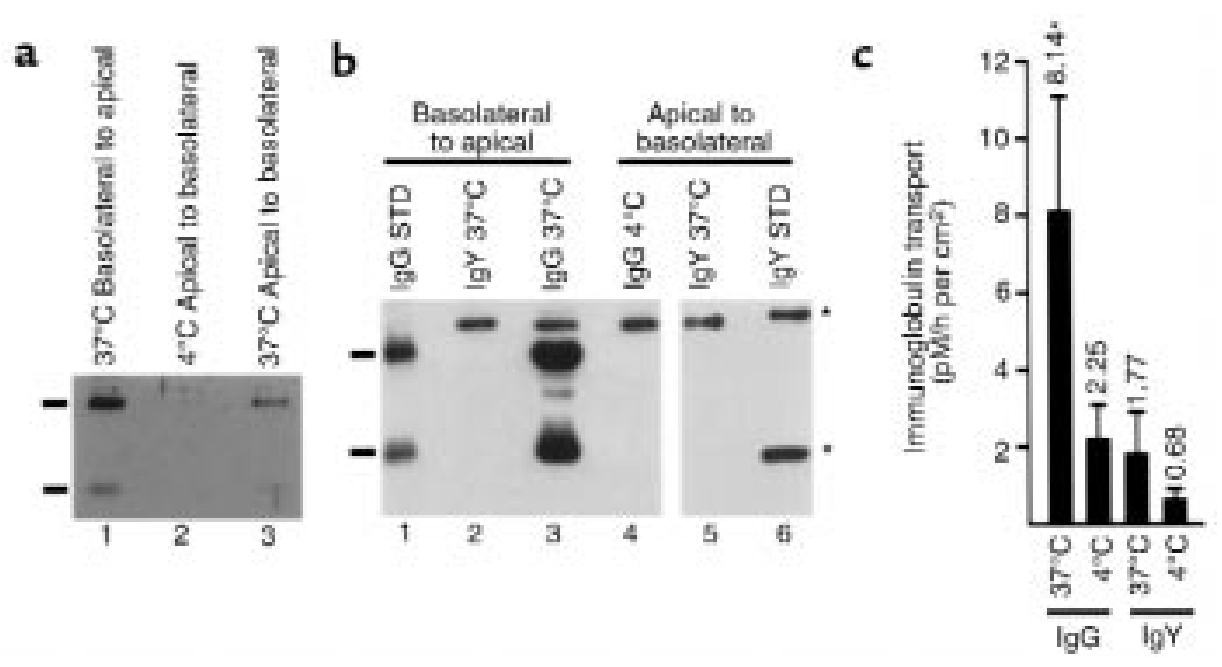

\section{Figure 5}

FcRn-dependent bidirectional transcytosis of IgG across T84 cell monolayers. (a) Transcytosis of IgG-biotin occurs at $37^{\circ} \mathrm{C}($ lanes 1 and 3 ) but not at $4^{\circ} \mathrm{C}$ (lane 2). (b) Specificity of IgG transport for FcRn. T84 cells transport human IgG-biotin at $37^{\circ} \mathrm{C}$ (lane 3 ) but not at $4^{\circ} \mathrm{C}$ (lane 4). IgG heavy and light chains are indicated by the bars to the left of the IgG standard. In contrast, chicken IgY-biotin does not cross T84 cell monolayers at $37^{\circ} \mathrm{C}$ in either direction (lanes 2 and 5). IgY heavy and light chains are indicated by asterisks to the right of the IgY standard. (c) Quantitative ELISA of IgG and IgY transport at $37^{\circ} \mathrm{C}$ and $4^{\circ} \mathrm{C}$. 


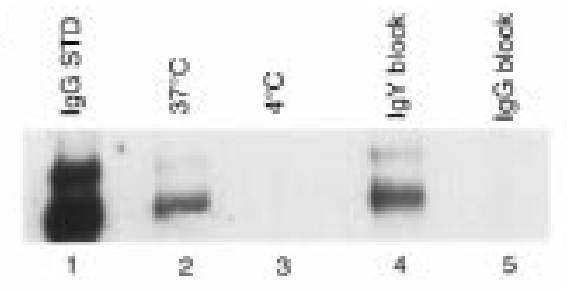

b

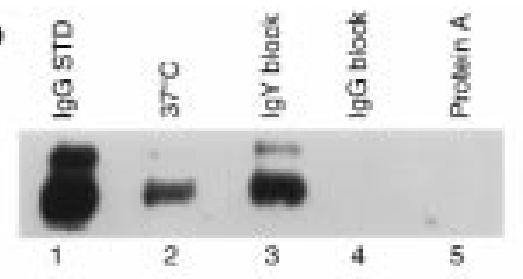

c

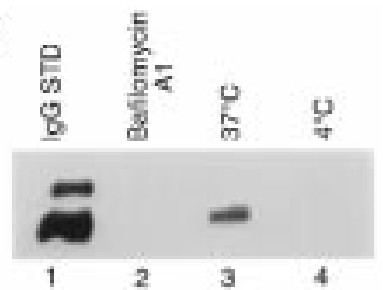

Figure 6

Specificity of IgG transport and functional dependence on the vacuolar $\mathrm{H}^{+}$ATPase. Where transport occured, the 25-kDa biotinylated light chain of IgG is shown. (a) Apical-to-basolateral transcytosis of IgG-biotin (60 nM) in the absence or presence of a 500 -fold molar excess of nonlabeled chicken $\operatorname{IgY}(30 \mu \mathrm{M})$ or human $\operatorname{lgG}(30 \mu \mathrm{M})$ (lanes 4 and 5, respectively). Lanes 2 and 3 show incubation in the absence of competitive inhibitor at $37^{\circ} \mathrm{C}$ and $4^{\circ} \mathrm{C}$ as positive and negative controls, respectively. (b) Basolateral-to-apical transcytosis of IgG-biotin (60 $\mathrm{nM})$ in the absence or presence of a 500 -fold molar excess of nonlabeled chicken $\operatorname{IgY}(30 \mu \mathrm{M})$ (lane 3 ) or human $\lg \mathrm{G}(30 \mu \mathrm{M})$ (lane 4$)$ or excess fragment B of Staphylococcal protein A $(0.1 \mathrm{mg} / \mathrm{mL}$; lane 5$)$. Lane 2 shows incubation at $37^{\circ} \mathrm{C}$ as a positive control. (c) T84 cells were incubated in the presence (lane 2 ) or absence (lanes 3 and 4 ) of bafilomycin A1 (0.1 $\mu \mathrm{M})$, and basolaterally directed transport of IgGbiotin $(60 \mathrm{nM})$ was measured after 1 hour of incubation in symmetrical HBSS+ buffered to $\mathrm{pH}$ 8.0.

for the pIgA-R. First, transcytosis by FcRn is bidirectional, as shown in this report. Second, unlike the PIgA-R, FcRn does not undergo proteolysis after delivering its ligand to the apical cell surface. Our data suggest instead that FcRn may reenter the cell for return to the opposite membrane. Thus, unlike the pIgA-R, which is committed to only 1 round of dimeric IgA transport, the same FcRn molecule may transport IgG for multiple rounds in both lumenal and ablumenal directions. Third, unlike the pIgA-R, FcRn may initially bind its ligand within acidic endosomes rather than at the cell surface. This concept is not new. In contrast to the rat and mouse neonatal intestine, where maternal IgG binds FcRn at the apical cell surface (47), FcRn expressed in the rat yolk sac appears to bind IgG only within apical compartments after fluidphase uptake (48). Also, Benlounes et al. (49) have observed transepithelial IgG transport across isolated neonatal rat intestine in which both the serosal and mucosal solutions were clamped at neutral $\mathrm{pH}$ and thus inhibitory for IgG binding to FcRn at the cell surface.

Several lines of evidence support the idea that FcRn, like the PIgA-R, may function in vivo to transport immunoglobulins across epithelial barriers. First, IgG is present in secretions of the human oral mucosa, small and large intestine, lung, and genitourinary tract $(50-53)$. The mechanism by which IgG is transported onto these mucosal surfaces is unknown. Some evidence suggests that lumenal IgG represents passive transudation from the serum. This view is challenged by studies that show that numbers of local IgG-secreting cells in mucosal tissues and levels of antigen-specific IgG in mucosal secretions can be dramatically increased after both mucosal and systemic immunization (54-60). In addition, Berneman et al. (57) have found that the patterns of IgG subclasses in human serum differ from those found in autologous secretions at mucosal surfaces, and demonstrate that the concentration of IgG subclasses differ from those found in the serum. These data provide evidence that IgG in lumenal secretions may be derived from local origin and transported selectively across mucosal barriers. Whether
FcRn mediates IgG transport in the adult human intestine, however, has not been tested directly.

On the other hand, the results of our in vitro studies on IgG transport across T84 cell monolayers predict that FcRn may function in vivo to establish and maintain a steady-state distribution of IgG across the epithelial barrier of the human intestine, and possibly across other mucosal surfaces that bear FcRn. Such a putative function would have important effects on IgG-mediated mucosal immunity and host defense by providing a mechanism for antigen transport to subepithelial lymphocytes in the absence of a disrupted epithelial barrier. We can envision that FcRn may deliver IgG across the epithelial barrier for recognition of cognate antigens in the lumen, and then may function in the opposite direction for delivery of immune complexes to lymphocytes in the lamina propria. In this regard, it is already well known that FcRn can transport antigen-antibody immune complexes across the intestine of suckling rodents (33). Thus, FcRn may effectively mediate a novel mechanism for immunosurveillance and host defense at mucosal sites.

\section{Acknowledgments}

We thank M.R. Neutra for critical reading of the manuscript, and Kevin McCarthy for use of the anti-human FcRn antibody. This work was supported by research grants from the National Institutes of Health (DK/AI53056 to W.I. Lencer and R.S. Blumberg; DK-48106 to W.I. Lencer; DK-44319 to R.S. Blumberg; HD-27691 and HD-01146 to N.E. Simister; and DK-34854 to the Harvard Digestive Diseases Center).

\footnotetext{
1. Brambell, F.W. 1966. The transmission of immunity from mother to young and the catabolism of immunoglobulins. Lancet. 2:1087-1093. 2. Simister, N.E., and Rees, A.R. 1985. Isolation and characterization of an Fc receptor from neonatal rat small intestine. Eur. J. Immunol. 15:733-738. 3. Simister, N.E., Story, C.M., Chen, H.L., and Hunt, J.S. 1996. An IgGtransporting $\mathrm{Fc}$ receptor expressed in the syncytiotrophoblast of human placenta. Eur. J. Immunol. 26:1527-1531.

4. Abrahamson, D.R., and Rodewald, R. 1981. Evidence for the sorting of endocytic vesicle contents during the receptor-mediated transport of $\operatorname{IgG}$ across the newborn rat intestine. J. Cell Biol. 91:270-280.

5. Simister, N.E., and Mostov, K.E. 1989. Cloning and expression of the neonatal rat intestinal $\mathrm{Fc}$ receptor, a major histocompatibility complex
} 
class I antigen homolog. Cold Spring Harb. Symp. Ouant. Biol. 54:571-580.

6. Kim, J.K., Tsen, M.F., Ghetie, V., and Ward, E.S. 1994. Localization of the site of the murine IgG1 molecule that is involved in binding to the murine intestinal Fc receptor. Eur. J. Immunol. 24:2429-2434.

7. Kim, J.K., Tsen, M.F., Ghetie, V., and Ward, E.S. 1994. Identifying amino acid residues that influence plasma clearance of murine IgG1 fragments by site-directed mutagenesis. Eur. J. Immunol. 24:542-548.

8. Kim, J.K., Tsen, M.F., Ghetie, V., and Ward, E.S. 1995. Evidence that the hinge region plays a role in maintaining serum levels of the murine IgG1 molecule. Mol. Immunol. 32:467-475.

9. Raghavan, M., Chen, M.Y., Gastinel, L.N., and Bjorkman, P.J. 1994. Investigation of the interaction between the class I MHC-related Fc receptor and its immunoglobulin G ligand. Immunity. 1:303-315.

10. Popov, S., et al. 1996. The stoichiometry and affinity of the interaction of murine Fc fragments with the MHC class I-related receptor, FcRn. Mol. Immunol. 33:521-530.

11. Vaughn, D.E., et al. 1997. Identification of critical IgG binding epitopes on the neonatal Fc receptor. J. Mol. Biol. 274:597-607.

12. Vaughn, D.E., and Bjorkman, P.J. 1998. Structural basis of pH-dependent antibody binding by the neonatal Fc receptor. Structure. 6:63-73.

13. Raghavan, M., Bonagura, V.R., Morrison, S.L., and Bjorkman, P.J. 1995 Analysis of the $\mathrm{pH}$ dependence of the neonatal Fc receptor/immunoglobulin G interaction using antibody and receptor variants. Biochemistry. 34:14649-14657.

14. Junghans, R.P. 1997. Finally: the Brambell receptor (FcRB). Mediator of transmission of immunity and protection from catabolism for IgG. Immunol. Res. 16:29-57.

15. Berryman, M., and Rodewald, R. 1995. Beta 2-microglobulin co-distributes with the heavy chain of the intestinal IgG-Fc receptor throughout the transepithelial transport pathway of the neonatal rat. J. Cell Sci. 108:2347-2360

16. Martin, M.G., Wu, S.V., and Walsh, J.H. 1997. Ontogenetic development and distribution of antibody transport and Fc receptor mRNA expression in rat intestine. Dig. Dis. Sci. 42:1062-1069.

17. Ghetie, V., et al. 1996. Abnormally short serum half-lives of IgG in beta 2-microglobulin-deficient mice. Eur. J. Immunol. 26:690-696.

18. Blumberg, R.S., et al. 1995. A major histocompatibility complex class Irelated Fc receptor for IgG on rat hepatocytes. J. Clin. Invest. 95:2397-2402.

19. Israel, E.J., et al. 1997. Expression of the neonatal Fc receptor, FcRn, on human intestinal epithelial cells. Immunology. 92:69-74.

20. Story, C.M., Mikulska, J.E., and Simister, N.E. 1994. A major histocompatibility complex class I-like Fc receptor cloned from human placenta: possible role in transfer of immunoglobulin $\mathrm{G}$ from mother to fetus. $J$. Exp. Med. 180:2377-2381.

21. Balk, S.P., et al. 1991. Oligoclonal expansion and CD1 recognition by human intestinal intraepithelial lymphocytes. Science. 253:1411-1415.

22. Blumberg, R.S., et al. 1991. Expression of a nonpolymorphic MHC class I-like molecule, CD1D, by human intestinal epithelial cells. J. Immunol. 147:2518-2524

23. Lencer, W.I., et al. 1993. Entry of cholera toxin into polarized human intestinal epithelial cells. Identification of an early brefeldin A sensitive event required for A1-peptide generation. J. Clin. Invest. 92:2941-2951.

24. Lencer, W.I., Moe, S., Rufo, P.A., and Madara, J.L. 1995. Transcytosis of cholera toxin subunits across model human intestinal epithelia. Proc. Natl. Acad. Sci. USA. 92:10094-10098.

25. Lencer, W.I., et al. 1995. Targeting of cholera toxin and Escherichia coli heat labile toxin in polarized epithelia: role of COOH-terminal KDEL. J. Cell Biol. 131:951-962.

26. Porges, A.J., et al. 1992. Novel Fc gamma receptor I family gene products in human mononuclear cells. J. Clin. Invest. 90:2102-2109.

27. van de Winkel, J.G., de Wit, T.P., Ernst, L.K., Capel, P.J., and Ceuppens, J.L. 1995. Molecular basis for a familial defect in phagocyte expression of IgG receptor I (CD64). J. Immunol. 154:2896-2903.

28. Ernst, L.K., van de Winkel, J.G., Chiu, I.M., and Anderson, C.L. 1992. Three genes for the human high affinity Fc receptor for IgG (Fc gamma RI) encode four distinct transcription products. J. Biol. Chem. 267:15692-15700.

29. Lencer, W.I., et al. 1995. Signal transduction by cholera toxin: processing in vesicular compartments does not require acidification. Am. J. Physiol. 269:G548-G557.

30. Wolf, A.A., et al. 1998. Ganglioside structure dictates signal transduction by cholera toxin and association with caveolae-like membrane domains in polarized epithelia. J. Cell Biol. 141:917-927.

31. Ravetch, J.V., and Kinet, J.P. 1991. Fc receptors. Annu. Rev. Immunol. 9:457-492.

32. Raghavan, M., Gastinel, L.N., and Bjorkman, P.J. 1993. The class I major histocompatibility complex related $\mathrm{Fc}$ receptor shows $\mathrm{pH}$-dependent stability differences correlating with immunoglobulin binding and release. Biochemistry. 32:8654-8660.

33. Rodewald, R. 1973. Intestinal transport of antibodies in the newborn rat. J. Cell Biol. 58:189-211.

34. Israel, E.J., Wilsker, D.F., Hayes, K.C., Schoenfeld, D., and Simister, N.E.
1996. Increased clearance of $\operatorname{IgG}$ in mice that lack beta 2-microglobulin: possible protective role of FcRn. Immunology. 89:573-578.

35. Deisenhofer, J. 1981. Crystallographic refinement and atomic models of a human $\mathrm{Fc}$ fragment and its complex with fragment B of protein A from Staphylococcus aureus at 2.9- and 2.8-A resolution. Biochemistry. 20:2361-2370.

36. Presley, J.F., Mayor, S., McGraw, T.E., Dunn, K.W., and Maxfield, F.R. 1997. Bafilomycin A1 treatment retards transferrin receptor recycling more than bulk membrane recycling. J. Biol. Chem. 272:13929-13936.

37. Maksymowych, A.B., and Simpson, L.L. 1998. Binding and transcytosis of botulinum neurotoxin by polarized human colon carcinoma cells. $J$. Biol. Chem. 273:21950-21957.

38. Clague, M.J., Urbe, S., Aniento, F., and Gruenberg, J. 1994. Vacuolar ATPase activity is required for endosomal carrier vesicle formation. $J$. Biol. Chem. 269:21-24.

39. Walker, W.A. 1979. Gastrointestinal host defence: importance of gut closure in control of macromolecular transport. Ciba Found. Symp. 70:201-219.

40. Weiner, M.L. 1988. Intestinal transport of some macromolecules in food. Food Chem. Toxicol. 26:867-880.

41. Harada, E., Hashimoto, Y., and Syuto, B. 1994. Orally administered spermine induces precocious intestinal maturation of macromolecular transport and disaccharidase development in suckling rats. Comp. Biochem. Physiol. A Physiol. 109:667-673.

42. Harada, E., Hashimoto, Y., and Syuto, B. 1994. Precocious cessation of intestinal macromolecular transport and digestive enzymes development by prostaglandin E2 in suckling rats. Comp. Biochem. Physiol. A Physiol. 109:245-253.

43. Mostov, K.E., and Blobel, G. 1982. A transmembrane precursor of secretory component. The receptor for transcellular transport of polymeric immunoglobulins. J. Biol. Chem. 257:11816-11821.

44. Apodaca, G., Katz, L.A., and Mostov, K.E. 1994. Receptor-mediated transcytosis of IgA in MDCK cells is via apical recycling endosomes. J. Cell Biol. 125:67-86.

45. Mostov, K.E., Kraehenbuhl, J.P., and Blobel, G. 1980. Receptor-mediated transcellular transport of immunoglobulin: synthesis of secretory component as multiple and larger transmembrane forms. Proc. Natl. Acad. Sci. USA. 77:7257-7261.

46. Futter, C.E., Pearse, A., Hewlett, L.J., and Hopkins, C.R. 1996. Multivesicular endosomes containing internalized EGF-EGF receptor complexes mature and then fuse directly with lysosomes. J. Cell Biol. 132:1011-1023.

47. Rodewald, R., Lewis, D.M., and Kraehenbuhl, J.P. 1983. Immunoglobulin $\mathrm{G}$ receptors of intestinal brush borders from neonatal rats. Ciba Found. Symp. 95:287-299.

48. Roberts, D.M., Guenthert, M., and Rodewald, R. 1990. Isolation and characterization of the $\mathrm{Fc}$ receptor from the fetal yolk sac of the rat. $J$. Cell Biol. 111:1867-1876.

49. Benlounes, N., et al. 1995. Intestinal transport and processing of immunoglobulin $\mathrm{G}$ in the neonatal and adult rat. Biol. Neonate. 67:254-263.

50. Haimovici, F., Mayer, K.H., and Anderson, D.J. 1997. Quantitation of HIV-1-specific IgG, IgA, and IgM antibodies in human genital tract secretions. J. Acquir. Immune Defic. Syndr. Hum. Retrovirol. 15:185-191.

51. Reynolds, H.Y. 1987. Identification and role of immunoglobulins in respiratory secretions. Eur. J. Respir. Dis. Suppl. 153:103-116.

52. Quan, C.P., Ruffet, E., Arihiro, K., Pires, R., and Bouvet, J.P. 1996. High affinity serum-derived Fab fragments as another source of antibodies in the gut lumen of both neonates and adults. Scand. J. Immunol. 44:108-114.

53. Waldmann, T.A., and Strober, W. 1969. Metabolism of immunoglobulins. Prog. Allergy. 13:1-110.

54. Kozlowski, P.A., Cu-Uvin, S., Neutra, M.R., and Flanigan, T.P. 1997. Comparison of the oral, rectal, and vaginal immunization routes for induction of antibodies in rectal and genital tract secretions of women. Infect. Immun 65:1387-1394.

55. Belec, L., et al. 1995. Cervicovaginal overproduction of specific IgG to human immunodeficiency virus (HIV) contrasts with normal or impaired IgA local response in HIV infection. J. Infect. Dis. 172:691-697.

56. Belec, L., et al. 1996. Cervicovaginal synthesis of IgG antibodies to the immunodominant 175-199 domain of the surface glycoprotein gp46 of human T-cell leukemia virus type I. J. Med. Virol. 50:42-49.

57. Berneman, A., Belec, L., Fischetti, V.A., and Bouvet, J.P. 1998. The specificity patterns of human immunoglobulin $\mathrm{G}$ antibodies in serum differ from those in autologous secretions. Infect. Immun. 66:4163-4168.

58. Bouvet, J.P., Belec, L., Pires, R., and Pillot, J. 1994. Immunoglobulin G antibodies in human vaginal secretions after parenteral vaccination. Infect. Immun. 62:3957-3961.

59. Artenstein, A.W., et al. 1997. Mucosal immune responses in four distinct compartments of women infected with human immunodeficiency virus type 1: a comparison by site and correlation with clinical information. J. Infect. Dis. 175:265-271.

60. Moldoveanu, Z., Clements, M.L., Prince, S.J., Murphy, B.R., and Mestecky, J. 1995. Human immune responses to influenza virus vaccines administered by systemic or mucosal routes. Vaccine. 13:1006-1012. 